\title{
Meta-Analyses of the Effects of Habitual Running on Indices of Health in Physically Inactive Adults
}

\author{
Luiz Carlos Hespanhol Junior ${ }^{1} \cdot J_{u l i a n}$ David Pillay ${ }^{2}$ - Willem van Mechelen ${ }^{1}$. \\ Evert Verhagen ${ }^{1}$ (D)
}

Published online: 16 July 2015

(c) The Author(s) 2015. This article is published with open access at Springerlink.com

\begin{abstract}
Background In order to implement running to promote physical activity, it is essential to quantify the extent to which running improves health.

Objective The aim was to summarise the literature on the effects of endurance running on biomedical indices of health in physically inactive adults.

Data Sources Electronic searches were conducted in October 2014 on PubMed, Embase, CINAHL, SPORTDiscus, PEDro, the Cochrane Library and LILACS, with no limits of date and language of publication.

Study Selection Randomised controlled trials (with a minimum of 8 weeks of running training) that included physically inactive but healthy adults (18-65 years) were selected. The studies needed to compare intervention (i.e.
\end{abstract}

Electronic supplementary material The online version of this article (doi:10.1007/s40279-015-0359-y) contains supplementary material, which is available to authorized users.

Evert Verhagen

e.verhagen@vumc.nl

Luiz Carlos Hespanhol Junior

1.hespanhol@outlook.com

Julian David Pillay

pillayjd@dut.ac.za

Willem van Mechelen

w.vanmechelen@vumc.nl

1 Department of Public and Occupational Health and the EMGO+ Institute for Health and Care Research, VU University Medical Center, Van der Boechorststraat 7. 1081 BT Amsterdam, The Netherlands

2 Department of Basic Medical Sciences, Durban University of Technology, PO Box 1334, Durban 4001, South Africa endurance running) and control (i.e. no intervention) groups.

Study Appraisal and Synthesis Methods Two authors evaluated study eligibility, extracted data, and assessed risk of bias; a third author resolved any uncertainties. Randomeffects meta-analyses were performed to summarise the estimates for length of training and sex. A dose-response analysis was performed with random-effects meta-regression in order to investigate the relationship between running characteristics and effect sizes.

Results After screening 22,380 records, 49 articles were included, of which 35 were used to combine data on ten biomedical indices of health. On average the running programs were composed of $3.7 \pm 0.9$ sessions/week, $2.3 \pm 1.0 \mathrm{~h} /$ week, $14.4 \pm 5.4 \mathrm{~km} /$ week, at 60-90\% of the maximum heart rate, and lasted $21.5 \pm 16.8$ weeks. After 1 year of training, running was effective in reducing body mass by $3.3 \mathrm{~kg}$ [95\% confidence interval (CI) 4.1-2.5], body fat by $2.7 \%$ (95\% CI 5.1-0.2), resting heart rate by $6.7 \mathrm{~min}^{-1}(95 \% \mathrm{CI} 10.3-3.0)$ and triglycerides by 16.9 $\mathrm{mg} \mathrm{dl}^{-1}$ (95\% CI 28.1-5.6). Also, running significantly increased maximal oxygen uptake $\left(V_{2 \max }\right)$ by 7.1

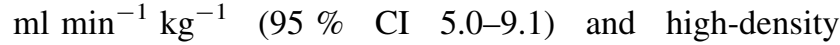
lipoprotein (HDL) cholesterol by $3.3 \mathrm{mg} \mathrm{dl}^{-1}$ (95\% CI 1.2-5.4). No significant effect was found for lean body mass, body mass index, total cholesterol and low-density lipoprotein cholesterol after 1 year of training. In the doseresponse analysis, larger effect sizes were found for longer length of training.

Limitations It was only possible to combine the data of ten out the 161 outcome measures identified. Lack of information on training characteristics precluded a multivariate model in the dose-response analysis.

Conclusions Endurance running was effective in providing substantial beneficial effects on body mass, body fat, 
resting heart rate, $V \mathrm{O}_{2 \max }$, triglycerides and HDL cholesterol in physically inactive adults. The longer the length of training, the larger the achieved health benefits. Clinicians and health authorities can use this information to advise individuals to run, and to support policies towards investing in running programs.

\section{Key Points}

Endurance running was found to be beneficial for health in physically inactive adults with regards to body mass, body fat, resting heart rate, maximal oxygen uptake, triglycerides and high-density lipoprotein cholesterol.

The effects of running on biomedical indices of health are beneficially correlated to running exposure.

Clinicians and health authorities can use this information to advise individuals to run, and also to support policies towards investing in running programs.

\section{Introduction}

Physical inactivity is a leading risk factor for mortality, accounting for millions of deaths per year [1]. Consequently, physical inactivity is a global public health concern [2] as a contributor to the worldwide epidemic of noncommunicable diseases [3]. Increasing physical activity levels throughout the population is a major challenge for the 21 st century $[2,4]$. Societal trends, nonetheless, show a steady decline in physical activity levels [4]. Commitment to change this scenario is therefore critical [2], and efforts are constantly made towards promoting a physically active lifestyle, the health benefits of which are well documented [5-8].

Regular running is a popular mode of physical activity [9], undertaken by many individuals seeking a healthier lifestyle [10]. It is easy to perform, it has a social component, and it is relatively inexpensive, time efficient and easily accessible $[10,11]$. The high popularity and accessibility of running is seen as a strong contributor towards promoting and enhancing a physically active lifestyle within the population [11]. In order to ensure effective running programs that promote physical activity, and consequently to reduce the risk of lifestyle-related diseases, it is essential to quantify the extent to which running improves health. Such information is valuable in identifying target populations for specific physical activity programs and, more importantly, towards increasing the effectiveness thereof [4]. The aim of this study was, therefore, to summarise the evidence on the effects of endurance running on biomedical indices of health in physically inactive adults.

\section{Methods}

\subsection{Eligibility Criteria}

Studies were considered for inclusion if they were randomised controlled trials published in peer-reviewed journals; included physically inactive but healthy adults (18-65 years) at baseline; studied an endurance type of running intervention; compared the effects of endurance running to a group not engaged in any physical activity intervention; provided a follow-up of 8 or more weeks; and included at least one biomedical health indicator (indices of health) as an outcome measure. Physically inactive participants were considered if the studies clearly stated that the participants were physically inactive or sedentary, or if they did not reach the physical activity recommendations at baseline [12].

Studies were not included if they aimed to evaluate the effects of running exclusively on performance or neuromuscular outcomes, as these were not considered to be general indices of health; involved a very specific sample that could be significantly different from the general population at baseline (e.g. obese) and, therefore, may respond differently to the running training, providing a biased estimate; provided an intervention composed of running in combination with something else (e.g. diet), as these interventions do not reflect the independent effect of running; and included less than 8 weeks of training, in order to ensure a reasonable time for physiological responses.

\subsection{Information Sources and Search Strategy}

Systematic electronic searches were conducted in October 2014 on PubMed, Embase, CINAHL, SPORTDiscus, PEDro, the Cochrane Library and LILACS. The searches were structured following the Cochrane Collaboration recommendations [13] and were not limited by date or language of publication. The detailed search strategy for each database can be found in Electronic Supplementary Material Appendix S1. Reference lists of included articles were also accessed to search for additional studies that might be eligible for inclusion. 


\subsection{Study Selection and Data Collection Process}

The selection process involved screening of titles and reading abstracts of the retrieved search results. The full texts of potentially relevant articles were subsequently obtained and analysed to check eligibility. The data were collected using a standardised data extraction form, which can be found in Electronic Supplementary Material Appendix S2. Two authors (LCHJ, JDP) evaluated the eligibility and extracted the relevant data of each article independently. In cases of uncertainty, a third author (EV) provided a consensus.

\subsection{Risk of Bias Assessment}

The risk of bias of all included studies was assessed by the Cochrane Collaboration's tool for assessing risk of bias of randomised trials [14]. This tool comprises seven items assessing selection bias (random sequence generation and allocation concealment), performance bias (blinding of participants and personnel), detection bias (blinding of outcome assessment), attrition bias (incomplete outcome data), reporting bias (selective reporting) and other sources of bias. In addition, it was assessed if the analysis was conducted on the basis of the intention-to-treat principle. The judgment was achieved in order to inform low risk of bias (i.e. criterion satisfied and clearly described in the article), high risk of bias (i.e. criterion not satisfied) and unclear risk of bias (i.e. insufficient information to permit judgment). Two authors (LCHJ, JDP) assessed each item independently, and in cases of uncertainties, a consensus was obtained through discussion and/or arbitration by a third author (EV).

\subsection{Data Analysis}

In order to summarise the effects of running on biomedical indices of health, the mean change from baseline and its standard deviation (SD) were used. In cases where the mean change from baseline was not available, but the study provided the mean at baseline and the mean after the follow-up, the mean change was calculated. In cases where the SD was not available, but the study provided another uncertainty measure as standard error or confidence intervals (CIs), the $\mathrm{SD}$ was estimated according to the Cochrane Collaboration recommendations [13]. Studies that did not provide sufficient data (e.g. number of participants, mean values or uncertainty measures for each group) were not included in the meta-analysis for that particular outcome. Duplicated results (articles related to the same study, but published as per different purposes) were considered in the meta-analysis only once for each outcome measure. The criteria used in deciding which duplicated result would be considered for the meta-analysis were based on (1) the primary aim of the study; (2) the date of publication, with preference for the earliest date; and (3) the number of participants, with preference for the largest sample available.

Random-effects meta-analyses were used to summarise the results of each outcome measure. The summary measure was the combined mean difference weighted by the inverse of the variance within and between (tau-squared) studies, and its $95 \%$ CI. Heterogeneity was assessed by the $I^{2}$ estimate. Subgroup analyses were performed in order to explain the effect variations by length of training and sex that were hypothesised before the analyses. Therefore, only the outcome measures that had at least ten comparisons between running and control groups were included in the meta-analysis, otherwise the subgroups analysis would not be possible. Outcome measures that did not meet this criterion were summarised descriptively.

A dose-response analysis was performed in order to investigate the relationship between running characteristics and effect sizes. Univariate linear meta-regressions with random effects were performed using the mean difference between running and control groups as the dependent variable (effect size), and the running characteristics (length of training, frequency, duration, distance, intensity and speed) as numeric linear predictors. Larger studies had more influence in the meta-regressions than smaller studies, and residual heterogeneity among effect sizes not modelled by the running characteristics was also considered in the analyses (random-effects) [13]. The summary measure was the linear regression coefficient $(\beta)$ and its $95 \%$ CI.

Meta-analyses and meta-regressions were conducted in Stata/SE 12.0 (StataCorp, College Station, Texas, USA), using the commands metan and metareg, respectively. Statistically significant results were considered for the estimates with the $95 \%$ CI not including zero [15].

\section{Results}

\subsection{Selection of the Studies}

A total of 22,380 records were retrieved, 22,353 from the electronic search strategy and 27 from references of included articles. Of the 17,875 unique records retrieved (duplicates removed), 49 articles were considered eligible. Only 35 articles, however, presented sufficient and original data and were, therefore, included in the meta-analysis. Figure 1 presents the flow diagram of the selection process. 


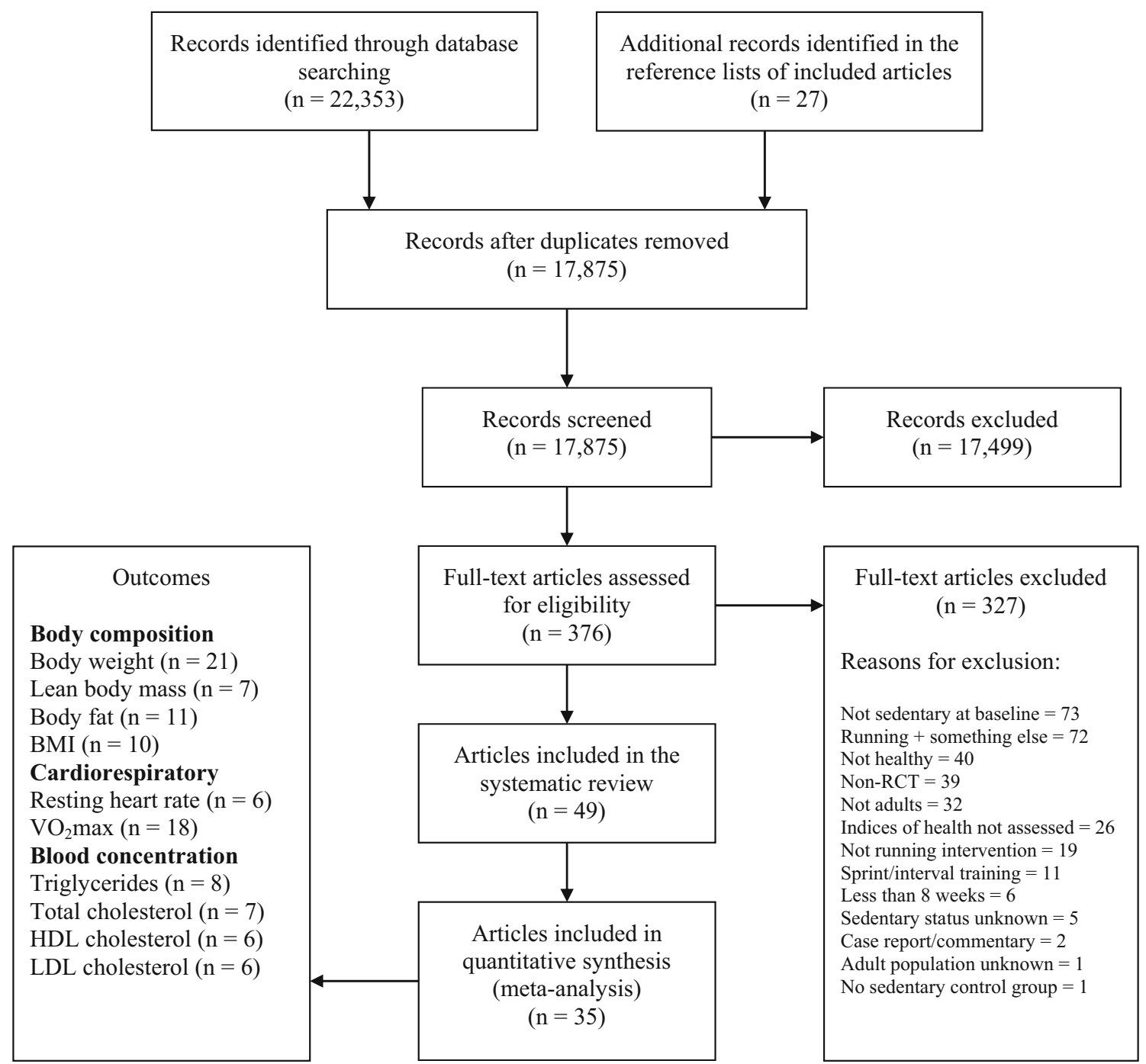

Fig. 1 Flow of the studies during the selection process. The databases searched were: PubMed, Embase, Cumulative Index to Nursing and Allied Health Literature (CINAHL), SPORTDiscus, Physiotherapy Evidence Database (PEDro), the Cochrane Library and

\subsection{Description of the Included Articles}

The 49 articles included in this systematic review were published between 1980 and 2014. The sample size ranged from 14 to 120 , with a mean of $41.3 \pm 25.5$ (mean \pm SD) participants. The total sample was composed of 2024 participants $(79 \%$ males, $n=1592 ; 21 \%$ females, $n=432$ ), aged $33.8 \pm 10.2$ years. In the control groups, the sample size ranged from 6 to $60(17.2 \pm 11.9)$, and the total was 844 participants (78 \% males, $n=658 ; 22 \%$ females, $n=186$ ), aged $34.1 \pm 9.9$ years.

In the running groups, the sample size ranged from 7 to $60(24.1 \pm 14.6)$, and the total was 1180 participants (79 \% males, $n=934 ; 21 \%$ females, $n=246$ ), aged $34.2 \pm 9.1$ years. On average the running programs were
Latin American and Caribbean Center on Health Sciences Information (LILACS). BMI body mass index, $H D L$ high-density lipoprotein, $L D L$ low-density lipoprotein, $R C T$ randomised controlled trial, $V O_{2 \max }$ maximal oxygen uptake

composed of $3.7 \pm 0.9$ sessions/week, $2.3 \pm 1.0 \mathrm{~h} /$ week, $14.4 \pm 5.4 \mathrm{~km} /$ week, and ranged from 60 to $90 \%$ of the maximum heart rate $(77.6 \pm 6.3 \%)$, and the length of training was $21.5 \pm 16.8$ weeks. Detailed description of the data extracted from the included articles can be found in Electronic Supplementary Material Appendix S2.

\subsection{Risk of Bias Assessment}

Table 1 presents the risk of bias assessment of all included articles. In general, underreporting of information was identified as a main concern. Consequently, it was difficult to judge certain criteria because of missing information. Most articles did not clearly describe the method of randomisation $(90 \%, n=44)$, whether the allocation of the 
Table 1 Risk of bias assessment of included studies

\begin{tabular}{|c|c|c|c|c|c|c|c|c|c|}
\hline \multirow[t]{2}{*}{ References } & \multirow[t]{2}{*}{ Year } & \multicolumn{7}{|c|}{ Cochrane Collaboration tool [14] } & \multirow{2}{*}{$\begin{array}{l}\text { Intention- } \\
\text { to-treat } \\
\text { analysis }\end{array}$} \\
\hline & & Randomisation & $\begin{array}{l}\text { Concealed } \\
\text { allocation }\end{array}$ & $\begin{array}{l}\text { Blinding of } \\
\text { participants } \\
\text { and personnel }\end{array}$ & $\begin{array}{l}\text { Blinding of } \\
\text { outcome } \\
\text { assessment }\end{array}$ & $\begin{array}{l}\text { Incomplete } \\
\text { outcome } \\
\text { data }\end{array}$ & $\begin{array}{l}\text { Selective } \\
\text { reporting }\end{array}$ & $\begin{array}{l}\text { Other } \\
\text { bias }\end{array}$ & \\
\hline $\begin{array}{l}\text { Moghadasi and } \\
\text { Mohammadi } \\
\text { Domieh [62] }\end{array}$ & 2014 & $?$ & $?$ & - & - & + & $?$ & + & $?$ \\
\hline Celik et al. [60] & 2013 & + & + & - & $\begin{array}{l}\text { Blood samples: + } \\
\text { Physical/physiological: } \\
\quad-\end{array}$ & + & $?$ & + & $?$ \\
\hline Gregory et al. [63] & 2013 & $?$ & $?$ & - & - & - & $?$ & + & $?$ \\
\hline Asad et al. [64] & 2012 & $?$ & $?$ & - & - & + & $?$ & + & $?$ \\
\hline Hosseini et al. [65] & 2012 & $?$ & $?$ & - & - & + & $?$ & + & $?$ \\
\hline Lo et al. [66] & 2011 & $?$ & $?$ & - & - & + & $?$ & + & $?$ \\
\hline Andersen et al. [67] & 2010 & $?$ & $?$ & - & $\begin{array}{l}\text { Echocardiography: }+ \\
V \mathrm{O}_{2 \max } / \text { tissue Doppler: } \\
\quad-\end{array}$ & + & $?$ & + & $?$ \\
\hline Hendrickson et al. [30] & 2010 & $?$ & $?$ & - & - & $?$ & - & + & $?$ \\
\hline Krustrup et al. [68] & 2010 & - & - & - & $\begin{array}{l}\text { Echocardiography: + } \\
\text { DXA, BP, RHR, FG: - }\end{array}$ & - & $?$ & + & $?$ \\
\hline Nindl et al. [69] & 2010 & $?$ & $?$ & - & - & + & - & + & $?$ \\
\hline Ozdemir et al. [61] & 2010 & $?$ & $?$ & - & - & + & $?$ & + & $?$ \\
\hline Sedlock et al. [25] & 2010 & $?$ & $?$ & - & - & + & $?$ & + & $?$ \\
\hline Lee et al. [70] & 2009 & $?$ & $?$ & - & - & + & $?$ & + & $?$ \\
\hline Lester et al. [71] & 2009 & + & $?$ & - & - & + & $?$ & + & $?$ \\
\hline Brixius et al. [72] & 2008 & $?$ & $?$ & - & - & + & $?$ & + & $?$ \\
\hline Meyer et al. [17] & 2007 & $?$ & $?$ & - & - & + & $?$ & + & $?$ \\
\hline $\begin{array}{l}\text { Ring-Dimitriou et al. } \\
\text { [31] }\end{array}$ & 2007 & $?$ & $?$ & - & $\begin{array}{l}\text { Blood samples: }+ \\
\text { BC, aerobic fitness: - }\end{array}$ & - & $?$ & + & $?$ \\
\hline Beneke and Hutler [36] & 2005 & $?$ & $?$ & - & - & + & $?$ & + & $?$ \\
\hline Hautala et al. [73] & 2004 & $?$ & $?$ & - & - & + & $?$ & + & $?$ \\
\hline Poehlman et al. [74] & 2000 & $?$ & $?$ & - & - & - & $?$ & + & $?$ \\
\hline Bourque et al. [75] & 1997 & $?$ & $?$ & - & - & - & - & + & $?$ \\
\hline $\begin{array}{l}\text { Hubinger and } \\
\text { Mackinnon [76] }\end{array}$ & 1996 & $?$ & $?$ & - & - & - & $?$ & + & $?$ \\
\hline Suter et al. [77] & 1994 & $?$ & $?$ & - & - & + & $?$ & + & $?$ \\
\hline Garber et al. [78] & 1992 & $?$ & $?$ & - & - & - & $?$ & + & $?$ \\
\hline Suter and Marti [26] & 1992 & $?$ & $?$ & - & - & + & $?$ & + & $?$ \\
\hline Williams et al. [79] & 1992 & $?$ & $?$ & - & - & + & $?$ & + & $?$ \\
\hline Oja et al. [33] & 1991 & $?$ & $?$ & - & - & + & - & + & $?$ \\
\hline Marti et al. [28] & 1990 & $?$ & $?$ & - & - & + & $?$ & + & + \\
\hline Suter et al. [29] & 1990 & $?$ & $?$ & - & - & + & $?$ & + & $?$ \\
\hline Williams et al. [80] & 1990 & $?$ & + & - & - & + & $?$ & + & $?$ \\
\hline Williams et al. [35] & 1990 & $?$ & $?$ & - & - & + & - & + & $?$ \\
\hline Moses et al. [18] & 1989 & $?$ & $?$ & - & - & - & - & + & $?$ \\
\hline Williams et al. [27] & 1989 & $?$ & $?$ & - & - & + & $?$ & + & $?$ \\
\hline Wood et al. [34] & 1988 & $?$ & + & - & - & + & $?$ & + & $?$ \\
\hline Juneau et al. [81] & 1987 & $?$ & $?$ & - & - & + & - & + & $?$ \\
\hline Allen et al. [32] & 1986 & $?$ & $?$ & - & - & + & $?$ & + & $?$ \\
\hline Gossard et al. [16] & 1986 & $?$ & $?$ & - & - & + & $?$ & + & $?$ \\
\hline Hagan et al. [82] & 1986 & $?$ & $?$ & - & - & + & - & + & $?$ \\
\hline Mueller et al. [19] & 1986 & $?$ & $?$ & - & - & $?$ & $?$ & + & $?$ \\
\hline Savage et al. [20] & 1986 & $?$ & $?$ & - & - & + & $?$ & + & $?$ \\
\hline Thomas et al. [83] & 1985 & $?$ & $?$ & - & - & - & $?$ & + & $?$ \\
\hline
\end{tabular}


Table 1 continued

\begin{tabular}{|c|c|c|c|c|c|c|c|c|c|}
\hline \multirow[t]{2}{*}{ References } & \multirow[t]{2}{*}{ Year } & \multicolumn{7}{|c|}{ Cochrane Collaboration tool [14] } & \multirow{2}{*}{$\begin{array}{l}\text { Intention- } \\
\text { to-treat } \\
\text { analysis }\end{array}$} \\
\hline & & Randomisation & $\begin{array}{l}\text { Concealed } \\
\text { allocation }\end{array}$ & $\begin{array}{l}\text { Blinding of } \\
\text { participants } \\
\text { and personnel }\end{array}$ & $\begin{array}{l}\text { Blinding of } \\
\text { outcome } \\
\text { assessment }\end{array}$ & $\begin{array}{l}\text { Incomplete } \\
\text { outcome } \\
\text { data }\end{array}$ & $\begin{array}{l}\text { Selective } \\
\text { reporting }\end{array}$ & $\begin{array}{l}\text { Other } \\
\text { bias }\end{array}$ & \\
\hline Iltis et al. [21] & 1984 & $?$ & $?$ & - & - & + & $?$ & + & $?$ \\
\hline Mathur and Toriola [23] & 1984 & $?$ & $?$ & - & - & + & $?$ & + & $?$ \\
\hline Thomas et al. [22] & 1984 & - & $?$ & - & - & - & $?$ & + & $?$ \\
\hline Toriola [24] & 1984 & $?$ & $?$ & - & - & + & $?$ & + & $?$ \\
\hline Williams et al. [84] & 1983 & $?$ & $?$ & - & - & - & $?$ & + & $?$ \\
\hline Wood et al. [85] & 1983 & $?$ & + & - & - & + & $?$ & + & $?$ \\
\hline Williams et al. [86] & 1982 & $?$ & $?$ & - & - & + & $?$ & + & $?$ \\
\hline Wilmore et al. [87] & 1980 & + & $?$ & - & - & + & - & + & $?$ \\
\hline
\end{tabular}

Source of bias: selection bias (randomisation and concealed allocation), performance bias (blinding of participants and personnel), detection bias (blinding of outcome assessment), attrition bias (incomplete outcome data: $>20 \%$ ), reporting bias (selective reporting) and other source of bias

$B C$ body composition, $B P$ blood pressure, $D X A$ dual energy X-ray absorptiometry, $F G$ fasting glucose, $R H R$ resting heart rate, $V O_{2 \max }$ maximal oxygen uptake, + low risk of bias (plausible bias unlikely to seriously alter the results), - high risk of bias (plausible bias that seriously weakens confidence in the results), ? unclear risk of bias (plausible bias that raises some doubt about the results)

participants to study groups was concealed (90\%,n=44), information on the study protocol $(82 \%, n=40)$ and whether or not the analysis was conducted on the basis of the intention-to-treat principle $(98 \%, n=48)$. A low risk of bias was achieved for most of the studies regarding incomplete outcome data $(73 \%, n=36)$ and other sources of bias $(100 \%, n=49)$. Blinding of participants provided the highest risk of bias, which can be expected because of the nature of the intervention.

\subsection{Effects of Running on Biomedical Indices of Health: Meta-Analysis}

A total of 161 biomedical indices of health were collectively investigated in the 49 articles included in the systematic review (Electronic Supplementary Material Appendix S3). Outcome measures were classified into three groups: body composition, cardiorespiratory measures and blood serum concentrations. Some of the studies compared more than one running group (i.e. high/moderate-intensity and low-intensity training [16-20]; 4- and 2-mile training [21, 22]; or 4.8-, 3.2 - and $1.6-\mathrm{km}$ training $[23,24])$ to a control group, allowing multiple comparisons.

Meta-analyses were possible for ten outcome measures, and the main findings are summarised in Table 2. Forest plots, with detailed information of the number of studies and the results of individual studies included in each meta-analysis can be found in Electronic Supplementary Material Appendix S4.

\subsubsection{Body Composition Outcomes}

Meta-analyses were possible for four body composition outcome measures: body mass, lean body mass, percentage body fat and body mass index (BMI). A statistically significant reduction was found for body mass and percentage body fat in favour of the running group after 1 year of training. A greater reduction was found in males for both of these outcome measures. Differences in lean body mass and BMI were not statistically significant.

\subsubsection{Cardiorespiratory Outcomes}

Meta-analyses were possible for two cardiorespiratory outcome measures: resting heart rate and maximal oxygen uptake $\left(V \mathrm{O}_{2 \max }\right.$ in $\left.\mathrm{ml} \mathrm{min}^{-1} \mathrm{~kg}^{-1}\right)$. A statistically significant reduction in resting heart rate was found after 12, 26 and 52 weeks, and also in males. Statistically significant increases in $V \mathrm{O}_{2 \max }$ were found for all subgroup categories, with a larger effect size after 1 year of training and in males. The longer the length of training, the larger the effect of running on resting heart rate and $V_{2} O_{2 \max }$.

\subsubsection{Blood Serum Concentration Outcomes}

Meta-analyses were possible for four blood serum concentration outcome measures: triglycerides, total cholesterol, high-density lipoprotein (HDL) cholesterol and lowdensity lipoprotein (LDL) cholesterol. Statistically significant reductions were found for triglycerides and statistically significant increases were found for HDL cholesterol in favour of the running group after 1 year of training and in males. Conflicting results were found for total cholesterol after 12 and 26 weeks of training. Differences in LDL cholesterol were not statistically significant. 


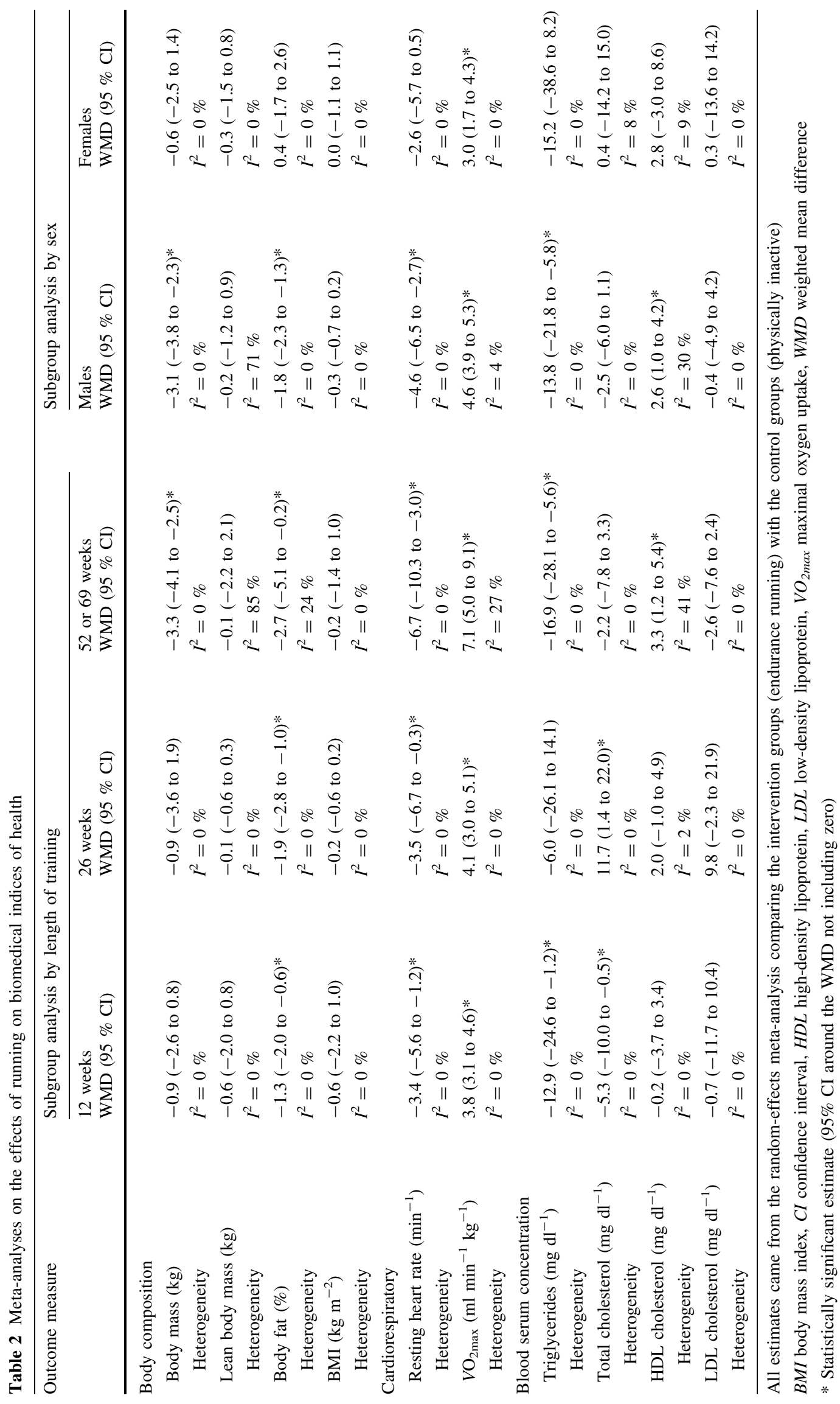




\subsubsection{Heterogeneity}

Table 2 presents results on heterogeneity. Most of the meta-analyses revealed low inconsistencies. Moderate heterogeneity was found in the meta-analyses for body fat $\left(I^{2}=24 \%\right), V \mathrm{O}_{2 \max }\left(I^{2}=27 \%\right)$ and HDL cholesterol $\left(I^{2}=41 \%\right)$ after 1 year of training, and for HDL cholesterol in males $\left(I^{2}=30 \%\right)$.

\subsection{Dose-Response Analysis: Meta-Regression}

A total of 34 articles $(97 \%)$ reported data on running frequency (sessions/week), 31 (89\%) on duration (h/week) and intensity (percentage of maximum heart rate), and nine $(26 \%)$ on distance $(\mathrm{km} /$ week). Sufficient data were provided in order to perform a dose-response analysis for length of training, running frequency, duration, distance and intensity. In addition, it was possible to calculate and analyse the average running speed by dividing the weekly distance by the weekly duration $(7.9 \pm 3.3 \mathrm{~km} / \mathrm{h})$ in nine articles $(26 \%)$.

Table 3 describes the meta-regression results. Longer length of training was statistically significantly associated with a reduction in body mass. Furthermore, longer length of training was statistically significantly associated with an increase in $V \mathrm{O}_{2 \max }$. Both associations indicated larger health benefits for longer running programs. However, an increase in weekly duration (h/week) was statistically significantly associated with a decrease in $V \mathrm{O}_{2 \max }$.

\subsection{Biomedical Indices of Health Not Included in the Meta-Analysis}

It was not possible to perform meta-analyses for 151 indices of health (Electronic Supplementary Material Appendix S3). Within the body composition category, there were only three outcome measures evaluated by more than two studies: body fat-free mass, sum of skin-folds and waist/hip ratio. Five studies evaluated body fat-free mass, with only one of these studies showing a statistically significant increase in the running group compared with the control group [25]. Seven studies evaluated the sum of skin-folds, two of which showed a statistically significant decrease in favour of the running group [20, 26]. One of these studies additionally found an increase in sum of skinfolds in the low-intensity running group compared with the control group [20]. Eight studies evaluated waist/hip ratio, one of which indicated a statistically significant decrease in favour of the running group [27], whilst two of the studies reported a statistically significant increase [28, 29].

Within the cardiorespiratory category, there were nine outcome measures evaluated by more than two studies: a change in submaximal heart rate at a fixed exercise intensity, left ventricular diameter in the end of the systole, left ventricular diameter at the end of the diastole, left ventricular posterior wall thickness at the end of the diastole, systolic blood pressure, diastolic blood pressure, peak oxygen uptake $\left(V \mathrm{O}_{2 \text { peak }}\right)$, maximum pulmonary ventilation $\left(\mathrm{VE}_{\max }\right)$ and respiratory exchange ratio. Of the five studies that evaluated $V \mathrm{O}_{2 \text { peak }}$, two studies found a statistically significant increase in favour of the running group [30,31]. Of the three studies that evaluated $\mathrm{VE}_{\max }$, two reported a statistically significant increase in favour of the running group [32, 33]. No statistically significant results were found for the other seven cardiorespiratory outcome measures.

Within the blood serum concentration category, there were 16 outcome measures evaluated by more than two studies: fasting glucose, fasting insulin, total cholesterol/ HDL ratio, HDL/total cholesterol ratio, lecithin:cholesterol acyltransferase (LCTA), HDL2 subfraction, HDL3 subfraction, small LDL, large LDL, LDL peak flotation rate, very low-density lipoprotein (VLDL), intermediate-density lipoprotein, apolipoprotein A-I, apolipoprotein A-II, apolipoprotein B and lactate. A statistically significant decrease, in favour of the running group, was found in one of the four studies that evaluated glucose [23] and total cholesterol/HDL ratio [34]. Of the seven studies that evaluated HDL2 and HDL3 subfractions, two studies found a statistically significant increase in favour of the running group $[34,35]$. Of the six studies that evaluated VLDL, two studies found a statistically significant decrease in favour of the running group $[28,35]$. Ten and nine studies evaluated apolipoprotein A-I and B, respectively. Only one study, however, found a statistically significant increase in favour of the running group for apolipoprotein A-I and a statistically significant decrease for apolipoprotein B [31]. Of the four studies that evaluated lactate, only one study found a statistically significant decrease in favour of the running group [36]. No statistically significant results were found for the other eight blood serum concentration outcome measures.

\section{Discussion}

This study was a comprehensive systematic review aiming to summarise the evidence about the effects of endurance running on biomedical indices of health. Running provided a beneficial effect on body mass, body fat, resting heart rate, $V \mathrm{O}_{2 \max }$, triglycerides and $\mathrm{HDL}$ cholesterol. In general, larger effects were observed with longer length of training and in males. With regards to the running dose, the results also suggested that the effect of running on body mass and $V \mathrm{O}_{2 \max }$ was larger with longer length of training. 


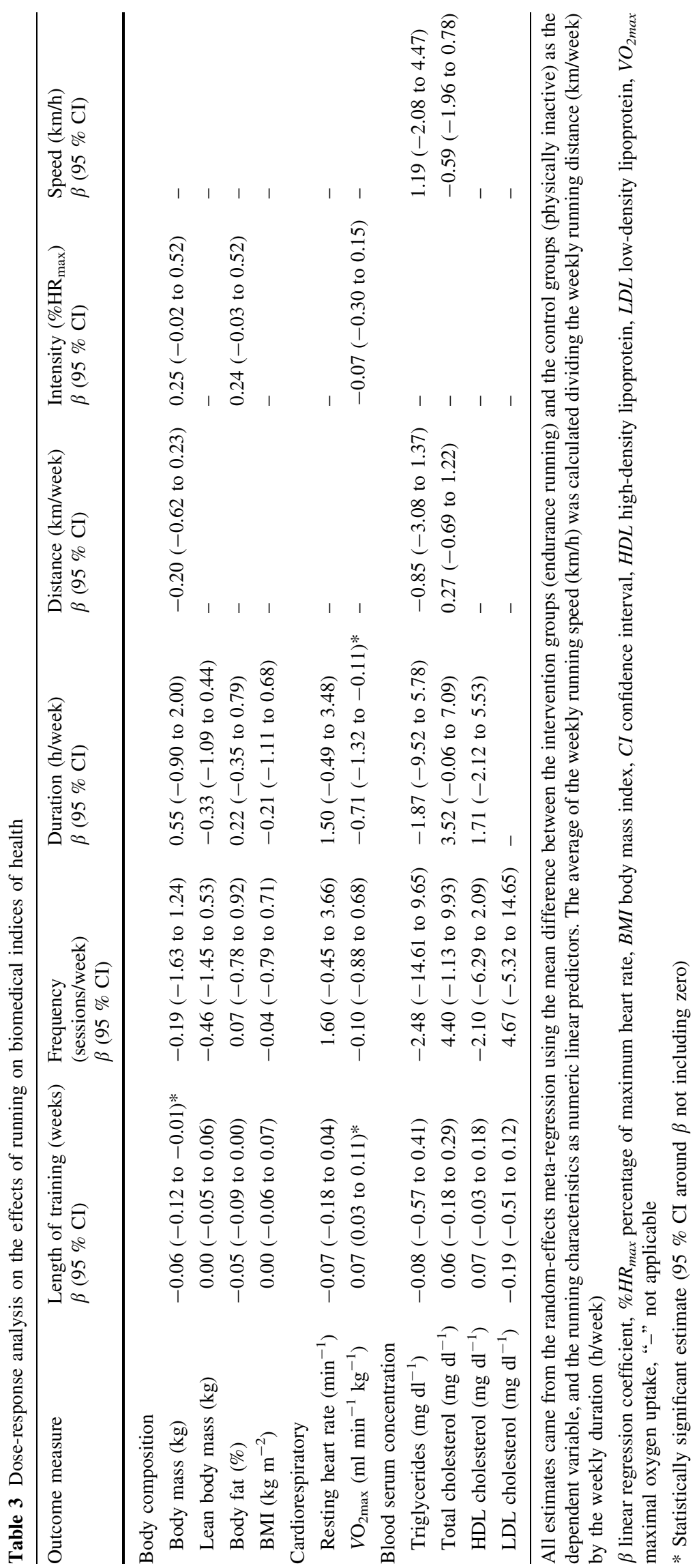




\subsection{Risk of Bias}

Underreporting was the main factor identified in the risk of bias assessment of the included randomised controlled trials. One explanation could be that most of the studies were published before the Consolidated Standards of Reporting Trials (CONSORT) statement [37]. Studies published after CONSORT, however, presented similar underreporting issues. Owing to the nature of the intervention, the blinding of participants and personnel presented a high risk of bias in all studies. The blinding of participants and personnel is challenging or almost impossible in physical activity interventions [37]. However, blinding of the outcome assessment is often achievable [37]. It was, therefore, surprising to note the high risk of bias judgment in most articles regarding blinding of outcome assessment. Researchers should be aware about reporting all relevant methodological information in randomised controlled trials, and also about designing studies with the lowest risk of bias as possible.

\subsection{Possible Mechanisms of the Effects of Endurance Running}

The reduction found in body mass can be explained by the reduction in percentage body fat with no significant changes in lean body mass. Prolonged endurance exercise training is known to increase lipids metabolism during exercise [38]. This is probably the most reasonable mechanism explaining the reduction in body fat (and consequently in body mass), and also explains the effect of running on triglycerides (an important fat substrate [39]) and on HDL cholesterol [40]. The reduction in resting heart rate could be explained by adaptations of exercise such as increases in blood volume [41] and reductions in sympathetic and/or increases in parasympathetic autonomic control at rest [42]. The increase in relative $V \mathrm{O}_{2 \max }\left(\mathrm{ml} \mathrm{min} \mathrm{mg}^{-1} \mathrm{~kg}^{-1}\right)$ could be partially explained by the reduction in body mass, and partially by physiological adaptions of exercise. Increases in stroke volume and cardiac output (as a result of the increased blood volume caused by the exercise training [41]) can increase the oxygen delivery [43].

Physical activity has been considered as a drug [44] because of the similarities in health benefits achieved by both [45]. An essential aspect of physical activity, therefore, relates to dosage [46]. The effects of running on body mass and $V \mathrm{O}_{2 \max }$ were larger for longer length of training ( 1 additional week of running training reduces the body mass by $0.06 \mathrm{~kg}$ and increases the $V \mathrm{O}_{2 \max }$ by $0.07 \mathrm{ml} \mathrm{min}^{-1} \mathrm{~kg}^{-1}$ ), and this trend was consistent with all other outcomes. There is an evident explanation for these results: the longer one exercises, the larger the benefits one achieves. However, larger effect sizes were achieved with shorter weekly duration for $V \mathrm{O}_{2 \max }$, and although this result was counterintuitive with our previous hypothesis, studies have shown that the duration of exercise per session is not a suitable characteristic to be manipulated in order to enhance cardiorespiratory outcomes [47, 48]. On the other hand, training intensity seems to play an important role [47-49], but the results of this systematic review were inconclusive in this regard.

\subsection{Implications for Practice}

Endurance running was found to be beneficial for health with regard to biomedical indices of health related to cardiovascular disease, and also presented beneficial doseresponse relationships. Clinicians can use the outcomes of the current systematic review to advise running in order to improve health in physically inactive adults. Outcomes of this review can also be used by (public) health authorities to support policies towards investing in running programs, therefore, combating physical inactivity, which is a leading risk factor for mortality [1]. This rationale is of particular significance for public health, as running is well known to be easily accessible and relatively inexpensive to implement $[10,11]$.

After evidencing that an intervention is effective, the next step is to evaluate if the intervention is implementable in the real world (i.e. in the non-controlled environment) [50]. One important aspect of implementation is to investigate whether or not individuals continue to adhere to the intervention after the study ends. Unfortunately, no studies included in this systematic review investigated this issue. However, Ooms et al. [11] showed that 4.5 months after the end of a 6-week start-to-run program, $69 \%$ of the participants in the start-to-run group were still running and they were spending 152 more min/week (95\% CI 80-223) in vigorous-intensity physical activities, and $107 \mathrm{more} \mathrm{min} /$ week (95\% CI 69-145) in sports activities compared with the control group. Therefore, available evidence suggests that promoting running in order to decrease physical inactivity is effective, beneficial for health, implementable and sustainable in the short term [11, 51, 52]. However, more studies investigating implementation issues of running programs are needed, especially in the long term.

The results of this systematic review were based on running programs designed for physically inactive adults. Therefore, the running volume and/or intensity were progressively increased and sometimes walking was allowed or an integral part of the running programs (detailed descriptions of the running programs can be found in Electronic Supplementary Material Appendix S2). This characteristic of the running programs could result in an underestimation of the effects of actual running on the biomedical indices of health [52]. Yet, 
the inclusion of walking reflects the reality of such programs in which participants walk every now and then [11]. Consequently, this increases the external validity of the results throughout the adult inactive population that decides to start running.

\subsection{Benefits Versus Risks of Running}

Despite the health benefits, running is not free from adverse effects. Although death during running is extremely rare (incidence of 0.39 per 100,000 runners) [53], running has a substantial risk of injuries [54]. The incidence of running injuries in novice runners is about 30 injuries per $1000 \mathrm{~h}$ of running exposure [55-57], and these injuries can affect up to $30 \%$ of novice runners in 1 year [58]. However, the health benefits achieved by running in physically inactive individuals outweigh the risks, since running significantly reduces much more severe outcomes, such as death (30 and $45 \%$ lower risk of all-cause and cardiovascular mortality, respectively) [52] and disability [51], which may be partially explained by the results of this systematic review.

\subsection{Limitations}

This systematic review was conducted in order to compare the running effects with no intervention. The advantages of this approach include the investigation of the crude effect of running and the comparability across studies. The main disadvantage is, however, that this study did not compare running with other types of physical activity, and it may be that other types of physical activity could reach similar health effects. According to Wen et al. [59], a 5-min run is as beneficial as a 15-min walk for the reduction of all-cause mortality; however, to get the same benefits as a 25 -min run, one should walk four times longer. Studies have shown that running, cycling and swimming training at the same volume and intensity result in similar effects on $V_{2} O_{2 \max }$ in physically inactive individuals $[60,61]$.

The limitations of this systematic review also include the following: of the 161 biomedical indices of health identified, it was only possible to combine the data for ten indices of health $(6 \%)$, which may have yielded an underestimation of the health benefits of endurance running; in some cases, the subgroup analyses were carried out with few studies, which may have limited the ability to draw strong conclusions about some subgroups; and the lack of a proper description of the training characteristics in some of the included papers precluded a multivariate meta-regression analysis investigating the influence of a combination of the training characteristics on the effect sizes.

\subsection{Future Recommendations}

Important areas for future research were identified on the basis of the current gaps noted. Few studies have investigated important biomedical indices of health, such as blood pressure, insulin and hormones, warranting the need for future studies that explore the effects of running on these indices. Studies included in this systematic review usually included males only; therefore, the effects on females should be further investigated. Most of the studies were conducted with a short follow-up; hence, more long-term studies should be conducted to investigate if the effects of running increase consistently over time or if there is a plateau in this relationship. Additionally, there is a need for studies investigating implementation issues regarding the continuation of running practice after organised running programs end (e.g. after the study has ended).

\section{Conclusions}

Current evidence supports that endurance running is effective in providing beneficial effects on body mass, body fat, resting heart rate, $V \mathrm{O}_{2 \max }$, triglycerides and $\mathrm{HDL}$ cholesterol in physically inactive adults. In general, the longer the length of training, the larger the achieved health benefits. Further research is necessary to investigate the effectiveness of running on biomedical indices of health for which there was insufficient evidence in this systematic review to enable conclusions to be drawn.

Acknowledgments Luiz Carlos Hespanhol Junior is a $\mathrm{PhD}$ candidate supported by CAPES (Coordenação de Aperfeiçoamento de Pessoal de Nível Superior), process number 0763/12-8, Ministry of Education of Brazil. This study had no funding source of any nature. All authors declare that there was no support from any organisation for the submitted work; no financial relationship with any organisation that might have an interest in the submitted work; and no other relationship or activities that could appear to have influenced the submitted work.

Open Access This article is distributed under the terms of the Creative Commons Attribution 4.0 International License (http:// creativecommons.org/licenses/by/4.0/), which permits unrestricted use, distribution, and reproduction in any medium, provided you give appropriate credit to the original author(s) and the source, provide a link to the Creative Commons license, and indicate if changes were made.

\section{References}

1. WHO. Global health risks: mortality and burden of disease attributable to selected major risks. Geneva: World Health Organization; 2009. 
2. Kohl HW, Craig CL, Lambert EV, et al. The pandemic of physical inactivity: global action for public health. Lancet. 2012;380(9838):294-305. doi:10.1016/S0140-6736(12)60898-8.

3. WHO. Global status report on noncommunicable diseases 2010. Geneva: World Health Organization; 2011.

4. Hallal PC, Andersen LB, Bull FC, et al. Global physical activity levels: surveillance progress, pitfalls, and prospects. Lancet. 2012;380(9838):247-57. doi:10.1016/S0140-6736(12)60646-1.

5. Pate RR, Pratt M, Blair SN, et al. Physical activity and public health. A recommendation from the Centers for Disease Control and Prevention and the American College of Sports Medicine. JAMA. 1995;273(5):402-7.

6. Slentz CA, Houmard JA, Kraus WE. Modest exercise prevents the progressive disease associated with physical inactivity. Exerc Sport Sci Rev. 2007;35(1):18-23. doi:10.1249/01.jes. 0000240019.07502.01.

7. Singh A, Uijtdewilligen L, Twisk JW, et al. Physical activity and performance at school: a systematic review of the literature including a methodological quality assessment. Arch Pediatr Adolesc Med. 2012;166(1):49-55. doi:10.1001/archpediatrics. 2011.716

8. Shrestha P, Ghimire L. A review about the effect of life style modification on diabetes and quality of life. Glob J Health Sci. 2012;4(6):185-90. doi:10.5539/gjhs.v4n6p185.

9. Stamatakis E, Chaudhury M. Temporal trends in adults' sports participation patterns in England between 1997 and 2006: the Health Survey for England. Br J Sports Med. 2008;42(11):901-8. doi:10.1136/bjsm.2008.048082.

10. Ottesen L, Jeppesen RS, Krustrup BR. The development of social capital through football and running: studying an intervention program for inactive women. Scand J Med Sci Sports. 2010;20(Suppl 1):118-31. doi:10.1111/j.1600-0838.2010.01123.x.

11. Ooms L, Veenhof C, de Bakker DH. Effectiveness of Start to Run, a 6-week training program for novice runners, on increasing health-enhancing physical activity: a controlled study. BMC Public Health. 2013;13:697. doi:10.1186/1471-2458-13-697.

12. Garber CE, Blissmer B, Deschenes MR, et al. American College of Sports Medicine position stand. Quantity and quality of exercise for developing and maintaining cardiorespiratory, musculoskeletal, and neuromotor fitness in apparently healthy adults: guidance for prescribing exercise. Med Sci Sports Exerc. 2011;43(7):1334-59. doi:10.1249/MSS.0b013e318213fefb.

13. Higgins JPT, Green S, editors. Cochrane handbook for systematic reviews of interventions version 5.1.0 [updated March 2011]. The Cochrane Collaboration, 2011. http://www.cochrane-handbook. org. Accessed 2 July 2015

14. Higgins JP, Altman DG, Gotzsche PC, et al. The Cochrane Collaboration's tool for assessing risk of bias in randomised trials. BMJ. 2011;343:d5928. doi:10.1136/bmj.d5928.

15. Gardner MJ, Altman DG. Confidence intervals rather than $P$ values: estimation rather than hypothesis testing. Br Med $\mathrm{J}$ (Clin Res Ed). 1986;292(6522):746-50.

16. Gossard D, Haskell WL, Taylor CB, et al. Effects of low- and high-intensity home-based exercise training on functional capacity in healthy middle-aged men. Am J Cardiol. 1986;57(6):446-9.

17. Meyer T, Auracher M, Heeg K, et al. Effectiveness of low-intensity endurance training. Int J Sports Med. 2007;28(1):33-9. doi:10.1055/s-2006-924037.

18. Moses J, Steptoe A, Mathews A, et al. The effects of exercise training on mental well-being in the normal population: a controlled trial. J Psychosom Res. 1989;33(1):47-61.

19. Mueller JK, Gossard D, Adams FR, et al. Assessment of prescribed increases in physical activity: application of a new method for microprocessor analysis of heart rate. Am J Cardiol. 1986;57(6):441-5.
20. Savage MP, Petratis MM, Thomson WH, et al. Exercise training effects on serum lipids of prepubescent boys and adult men. Med Sci Sports Exerc. 1986;18(2):197-204.

21. Iltis PW, Thomas TR, Adeniran SB, et al. Different running programs: plasma lipids, apoproteins, and lecithin: cholesterol acyltransferase in middle-aged men. Ann Sports Med. 1984;2(1):16-22.

22. Thomas TR, Adeniran SB, Etheridge GL. Effects of different running programs on $\mathrm{VO} 2$ max, percent fat, and plasma lipids. Can J Appl Sport Sci. 1984;9(2):55-62.

23. Mathur DN, Toriola AL. Twelve weeks jogging effects on selected cardiovascular risk factors in untrained healthy males. J Sports Med Phys Fitness. 1984;24(3):259-62.

24. Toriola AL. Influence of 12 -week jogging on body fat and serum lipids. Br J Sports Med. 1984;18(1):13-7.

25. Sedlock DA, Lee MG, Flynn MG, et al. Excess postexercise oxygen consumption after aerobic exercise training. Int J Sport Nutr Exerc Metab. 2010;20(4):336-49.

26. Suter E, Marti B. Little effect of long-term, self-monitored exercise on serum lipid levels in middle-aged women. J Sports Med Phys Fitness. 1992;32(4):400-11.

27. Williams PT, Krauss RM, Vranizan KM, et al. Effects of exercise-induced weight loss on low density lipoprotein subfractions in healthy men. Arteriosclerosis. 1989;9(5):623-32.

28. Marti B, Suter E, Riesen WF, et al. Effects of long-term, selfmonitored exercise on the serum lipoprotein and apolipoprotein profile in middle-aged men. Atherosclerosis. 1990;81(1):19-31.

29. Suter E, Marti B, Tschopp A, et al. Effects of self-monitored jogging on physical fitness, blood pressure and serum lipids: a controlled study in sedentary middle-aged men. Int J Sports Med. 1990;11(6):425-32. doi:10.1055/s-2007-1024832.

30. Hendrickson NR, Sharp MA, Alemany JA, et al. Combined resistance and endurance training improves physical capacity and performance on tactical occupational tasks. Eur J Appl Physiol. 2010;109(6):1197-208. doi:10.1007/s00421-010-1462-2.

31. Ring-Dimitriou S, von Duvillard SP, Paulweber B, et al. Nine months aerobic fitness induced changes on blood lipids and lipoproteins in untrained subjects versus controls. Eur J Appl Physiol. 2007;99(3):291-9. doi:10.1007/s00421-006-0347-x.

32. Allen D, Freund BJ, Wilmore JH. Interaction of test protocol and horizontal run training on maximal oxygen uptake. Med Sci Sports Exerc. 1986;18(5):581-7.

33. Oja P, Laukkanen RM, Kukkonen-Harjula TK, et al. Training effects of cross-country skiing and running on maximal aerobic cycle performance and on blood lipids. Eur J Appl Physiol Occup Physiol. 1991;62(6):400-4.

34. Wood PD, Stefanick ML, Dreon DM, et al. Changes in plasma lipids and lipoproteins in overweight men during weight loss through dieting as compared with exercise. N Engl J Med. 1988;319(18):1173-9. doi:10.1056/NEJM198811033191801.

35. Williams PT, Krauss RM, Vranizan KM, et al. Changes in lipoprotein subfractions during diet-induced and exercise-induced weight loss in moderately overweight men. Circulation. 1990;81(4):1293-304.

36. Beneke R, Hutler M. The effect of training on running economy and performance in recreational athletes. Med Sci Sports Exerc. 2005;37(10):1794-9.

37. Moher D, Hopewell S, Schulz KF, et al. CONSORT 2010 explanation and elaboration: updated guidelines for reporting parallel group randomised trials. $\mathrm{J}$ Clin Epidemiol. 2010;63(8):e1-37. doi:10.1016/j.jclinepi.2010.03.004.

38. Romijn JA, Coyle EF, Sidossis LS, et al. Regulation of endogenous fat and carbohydrate metabolism in relation to exercise intensity and duration. Am J Physiol. 1993;265(3 Pt 1):E380-91.

39. Hurley BF, Nemeth PM, Martin WH 3rd, et al. Muscle triglyceride utilization during exercise: effect of training. J Appl Physiol (1985). 1986;60(2):562-7. 
40. Kodama S, Tanaka S, Saito K, et al. Effect of aerobic exercise training on serum levels of high-density lipoprotein cholesterol: a meta-analysis. Arch Intern Med. 2007;167(10):999-1008. doi:10. 1001/archinte.167.10.999.

41. Oscai LB, Williams BT, Hertig BA. Effect of exercise on blood volume. J Appl Physiol. 1968;24(5):622-4.

42. Smith ML, Hudson DL, Graitzer HM, et al. Exercise training bradycardia: the role of autonomic balance. Med Sci Sports Exerc. 1989;21(1):40-4.

43. Krip B, Gledhill N, Jamnik V, et al. Effect of alterations in blood volume on cardiac function during maximal exercise. Med Sci Sports Exerc. 1997;29(11):1469-76.

44. Vina J, Sanchis-Gomar F, Martinez-Bello V, et al. Exercise acts as a drug: the pharmacological benefits of exercise. Br J Pharmacol. 2012;167(1):1-12. doi:10.1111/j.1476-5381.2012.01970. $\mathrm{x}$.

45. Naci H, Ioannidis JP. Comparative effectiveness of exercise and drug interventions on mortality outcomes: metaepidemiological study. BMJ. 2013;347:f5577. doi:10.1136/bmj.f5577.

46. Sattelmair J, Pertman J, Ding EL, et al. Dose response between physical activity and risk of coronary heart disease: a metaanalysis. Circulation. 2011;124(7):789-95. doi:10.1161/ CIRCULATIONAHA.110.010710.

47. Shephard RJ. Intensity, duration and frequency of exercise as determinants of the response to a training regime. Int $\mathrm{Z}$ Angew Physiol. 1968;26(3):272-8.

48. Wenger HA, Bell GJ. The interactions of intensity, frequency and duration of exercise training in altering cardiorespiratory fitness. Sports Med. 1986;3(5):346-56.

49. Midgley AW, McNaughton LR, Jones AM. Training to enhance the physiological determinants of long-distance running performance: can valid recommendations be given to runners and coaches based on current scientific knowledge? Sports Med. 2007;37(10):857-80.

50. Durlak JA, DuPre EP. Implementation matters: a review of research on the influence of implementation on program outcomes and the factors affecting implementation. Am J Community Psychol. 2008;41(3-4):327-50. doi:10.1007/s10464-0089165-0.

51. Chakravarty EF, Hubert HB, Lingala VB, et al. Reduced disability and mortality among aging runners: a 21-year longitudinal study. Arch Intern Med. 2008;168(15):1638-46. doi:10.1001/ archinte.168.15.1638.

52. Lee DC, Pate RR, Lavie CJ, et al. Leisure-time running reduces all-cause and cardiovascular mortality risk. J Am Coll Cardiol. 2014;64(5):472-81. doi:10.1016/j.jacc.2014.04.058.

53. Kim JH, Malhotra R, Chiampas G, et al. Cardiac arrest during long-distance running races. N Engl J Med. 2012;366(2):130-40. doi:10.1056/NEJMoa1106468.

54. Lopes AD, Hespanhol Junior LC, Yeung SS, et al. What are the main running-related musculoskeletal injuries? A systematic review. Sports Med. 2012;42(10):891-905. doi:10.2165/ 11631170-000000000-00000.

55. Buist I, Bredeweg SW, Bessem B, et al. Incidence and risk factors of running-related injuries during preparation for a 4-mile recreational running event. $\mathrm{Br} \mathrm{J}$ Sports Med. 2010;44(8):598-604. doi:10.1136/bjsm.2007.044677.

56. Buist I, Bredeweg SW, Lemmink KA, et al. Predictors of running-related injuries in novice runners enrolled in a systematic training program: a prospective cohort study. Am J Sports Med. 2010;38(2):273-80. doi:10.1177/0363546509347985.

57. Kluitenberg B, van Middelkoop M, Smits DW, et al. The NLstart2run study: incidence and risk factors of running-related injuries in novice runners. Scand J Med Sci Sports. 2014. doi:10. $1111 /$ sms. 12346.
58. Nielsen RO, Buist I, Parner ET, et al. Predictors of runningrelated injuries among 930 novice runners: a 1-year prospective follow-up study. Orthop J Sports Med. 2013;1(1):1-7.

59. Wen CP, Wai JP, Tsai MK, et al. Minimal amount of exercise to prolong life: to walk, to run, or just mix it up? J Am Coll Cardiol. 2014;64(5):482-4. doi:10.1016/j.jacc.2014.05.026.

60. Celik O, Salci Y, Ak E, et al. Serum cartilage oligomeric matrix protein accumulation decreases significantly after 12 weeks of running but not swimming and cycling training-a randomised controlled trial. Knee. 2013;20(1):19-25. doi:10.1016/j.knee. 2012.06.001.

61. Ozdemir RA, Celik O, Asci FH. Exercise interventions and their effects on physical self-perceptions of male university students. Int J Psychol. 2010;45(3):174-81. doi:10.1080/ 00207590903473750

62. Moghadasi M, Mohammadi Domieh A. Effects of resistance versus endurance training on plasma lipocalin-2 in young men. Asian. J Sports Med. 2014;4(6):108-14.

63. Gregory SM, Spiering BA, Alemany JA, et al. Exercise-induced insulin-like growth factor I system concentrations after training in women. Med Sci Sports Exerc. 2013;45(3):420-8. doi:10.1249/ MSS.0b013e3182750bd4.

64. Asad M, Ravasi AA, Faramarzi M, et al. The effects of three training methods endurance, resistance and concurrent on adiponectin resting levels in overweighed untrained men. Bratisl Lek Listy. 2012;113(11):664-8.

65. Hosseini M, Piri M, Agha-Alinejad $\mathrm{H}$, et al. The effect of endurance, resistance and concurrent training on the heart structure of female students. Biol Sport. 2012;29(1):17-21.

66. Lo MS, Lin LL, Yao WJ et al. Training and detraining effects of the resistance vs. endurance program on body composition, body size, and physical performance in young men. J Strength Cond Res. 2011;25(8):2246-54. doi:10.1519/JSC.0b013e3181e8a4be.

67. Andersen LJ, Hansen PR, Sogaard P, et al. Improvement of systolic and diastolic heart function after physical training in sedentary women. Scand J Med Sci Sports. 2010;20(Suppl 1):50-7. doi:10.1111/j.1600-0838.2009.01088.x.

68. Krustrup P, Hansen PR, Andersen LJ, et al. Long-term musculoskeletal and cardiac health effects of recreational football and running for premenopausal women. Scand J Med Sci Sports. 2010;20(Suppl 1):58-71. doi:10.1111/j.1600-0838.2010.01111.x.

69. Nindl BC, Alemany JA, Tuckow AP et al. Circulating bioactive and immunoreactive IGF-I remain stable in women, despite physical fitness improvements after 8 weeks of resistance, aerobic, and combined exercise training. J Appl Physiol (1985). 2010;109(1):112-20. doi:10.1152/japplphysiol.00025.2010.

70. Lee MG, Sedlock DA, Flynn MG, et al. Resting metabolic rate after endurance exercise training. Med Sci Sports Exerc. 2009;41(7):1444-51. doi:10.1249/MSS.0b013e31819bd617.

71. Lester ME, Urso ML, Evans RK, et al. Influence of exercise mode and osteogenic index on bone biomarker responses during shortterm physical training. Bone. 2009;45(4):768-76. doi:10.1016/j. bone.2009.06.001.

72. Brixius K, Schoenberger S, Ladage D et al. Long-term endurance exercise decreases antiangiogenic endostatin signalling in overweight men aged 50-60 years. $\mathrm{Br} \mathrm{J}$ Sports Med. 2008;42(2):126-9. doi:10.1136/bjsm.2007.035188 (discussion 9).

73. Hautala AJ, Makikallio TH, Kiviniemi A, et al. Heart rate dynamics after controlled training followed by a home-based exercise program. Eur J Appl Physiol. 2004;92(3):289-97. doi:10.1007/s00421-004-1077-6.

74. Poehlman ET, Dvorak RV, DeNino WF, et al. Effects of resistance training and endurance training on insulin sensitivity in nonobese, young women: a controlled randomized trial. J Clin 
Endocrinol Metab. 2000;85(7):2463-8. doi:10.1210/jcem.85.7. 6692.

75. Bourque SP, Pate RR, Branch JD. Twelve weeks of endurance exercise training does not affect iron status measures in women. J Am Diet Assoc. 1997;97(10):1116-21. doi:10.1016/S00028223(97)00272-1.

76. Hubinger L, Mackinnon LT. The effect of endurance training on lipoprotein(a) $[\mathrm{Lp}(\mathrm{a})]$ levels in middle-aged males. Med Sci Sports Exerc. 1996;28(6):757-64.

77. Suter E, Marti B, Gutzwiller F. Jogging or walking — comparison of health effects. Ann Epidemiol. 1994;4(5):375-81.

78. Garber CE, McKinney JS, Carleton RA. Is aerobic dance an effective alternative to walk-jog exercise training? J Sports Med Phys Fitness. 1992;32(2):136-41.

79. Williams PT, Krauss RM, Vranizan KM, et al. Effects of weightloss by exercise and by diet on apolipoproteins A-I and A-II and the particle-size distribution of high-density lipoproteins in men. Metabolism. 1992;41(4):441-9.

80. Williams PT, Albers JJ, Krauss RM, et al. Associations of lecithin: cholesterol acyltransferase (LCAT) mass concentrations with exercise, weight loss, and plasma lipoprotein subfraction concentrations in men. Atherosclerosis. 1990;82(1-2):53-8.
81. Juneau M, Rogers F, De Santos V, et al. Effectiveness of selfmonitored, home-based, moderate-intensity exercise training in middle-aged men and women. Am J Cardiol. 1987;60(1):66-70.

82. Hagan RD, Upton SJ, Wong L, et al. The effects of aerobic conditioning and/or caloric restriction in overweight men and women. Med Sci Sports Exerc. 1986;18(1):87-94.

83. Thomas TR, Adeniran SB, Iltis PW, et al. Effects of interval and continuous running on HDL-cholesterol, apoproteins A-1 and B, and LCAT. Can J Appl Sport Sci. 1985;10(1):52-9.

84. Williams PT, Wood PD, Krauss RM, et al. Does weight loss cause the exercise-induced increase in plasma high density lipoproteins? Atherosclerosis. 1983;47(2):173-85.

85. Wood PD, Haskell WL, Blair SN, et al. Increased exercise level and plasma lipoprotein concentrations: a one-year, randomized, controlled study in sedentary, middle-aged men. Metabolism. 1983;32(1):31-9.

86. Williams PT, Wood PD, Haskell WL, et al. The effects of running mileage and duration on plasma lipoprotein levels. JAMA. 1982;247(19):2674-9.

87. Wilmore JH, Davis JA, O'Brien RS, et al. Physiological alterations consequent to 20-week conditioning programs of bicycling, tennis, and jogging. Med Sci Sports Exerc. 1980;12(1):1-8. 